\title{
Identification of the Emotional Regulations of Surabaya Junior High School Students on the Tendency of Bullying Behavior
}

\author{
Elisabeth Christiana ${ }^{1, *}$ Nur Hidayah ${ }^{1}$ Blasius B. Lasan ${ }^{1}$ O.M. Hambali ${ }^{1}$
}

\author{
${ }^{1}$ Universitas Negeri Malang \\ *Corresponding author. Email: elisabethchristiana@unesa.ac.id
}

\begin{abstract}
This study aims to determine the level of emotional regulation of junior high school students in Surabaya on bullying behavior. This study is a comparative study with a sample of 135 students ( 80 female students, 55 male students). This study is a quantitative study with a descriptive approach. The instrument used is the scale of emotion regulation developed by Gross, JJ, \& John, OP. Analysis of the data used to identify students' level of emotional regulation is the independent samples test. The research findings show that there is a significant difference regulation of students' emotions. This study recommends counseling services to improve students' emotional regulation.
\end{abstract}

Keywords: Emotion Regulation, Bullying.

\section{INTRODUCTION}

Adolescence is divided into three phases, namely: the age of 12-15 years is called early adolescence, which is characterized by physical changes such as accelerated growth, cognitive and emotional maturity; ages $15-18$ years are called middle adolescence and ages 18-21 years are called late adolescence. Students who are in junior high school are included in the early adolescent phase. Rapid adolescent psychological changes can trigger a problem. Data from the 2018 Program for International Students Assessment (PISA) research shows that Indonesia is in the fifth highest position out of 78 countries, with the most students experiencing bullying. This condition then forces adolescents to maximize their potential in managing their emotions so that maladaptive behavior can be avoided properly. A person's ability to control his own emotions is often referred to as the regulation of emotions. Emotion regulation is an intrinsic experience in managing emotions which are then informed on the cognitive ability to exert emotional influence and feelings on behavior. The regulation of emotions itself is one way that can be done to help students facilitate their emotional needs. Many students tend to display maladaptive behavior as a result of their inability to manage their emotions. This study aims to identify the level of emotional regulation of bullying behavior tendencies. This research can be used as the basis for appropriate and meaningful counseling interventions. Counseling male and female students to improve their emotional regulation should be tailored to their needs.

\section{RESEARCH METHODS}

This study uses quantitative research with a descriptive approach. The population is 8th-grade students of SMPN Surabaya. Which are male and female.

Cognitive reassessment and expressive emphasis. The instrument used in this study is an emotion regulation scale developed by Gross, JJ, \& John, OP, with cognitive Reassessment and Expressive Emphasis [2]. This is adjusted to the multicultural characteristics of the research subjects by using validity and reliability tests. The application of this emotional regulation scale is equally adapted to the psychological development of junior high school students.

Data analysis was carried out using the independent sample test technique with the help of SPSS 20.00. The purpose of this analysis is to identify differences in the level of emotion regulation ability between male and female students. The results will be used to determine the difference between using cognitive reappraisal and expressive suppression indicators. The first thing to do is coordinate with school counselors to determine the sample involved in the study. Second, measure the level 
of emotion regulation in a sample of men and women. All data were entered into SPSS 20.00, and all necessary analyzes were performed.

\section{RESULTS}

The results of data analysis with the independent sample test formula are presented in table 1 and table 2 . Based on the results of statistical analysis of research data, descriptive data hypothetically shows the emotional regulation scale consists of 10 items with a minimum number of answers of the subject (Xmin) is 22 , the maximum answer of the subject $(\mathrm{Xmax})$ is 45 , the mean value of the subject (Mean) is 33.69990 (34), and the standard deviation of the subject (SD) is 4.72547

From the screening results, 135 students were obtained, consisting of 55 male students and 80 female students. This shows that the emotional tendencies of SMPN Surabaya students are in a low category, as many as $13 \%$ of students, the medium category is $73 \%$, the high category is $17 \%$.

Table 1. Description of research data results

\begin{tabular}{|l|l|l|}
\hline \multicolumn{3}{|c|}{ Descriptive Statistics } \\
\hline & TOTAL & $\begin{array}{l}\text { Valid N } \\
\text { (listwise) }\end{array}$ \\
\hline N & 135 & 135 \\
\hline Minimal & 22.00 & \\
\hline Maximal & 47.00 & \\
\hline Mean & 34.13 & \\
\hline Std. Deviation & 5.40287 & \\
\hline
\end{tabular}

Table 2. Categorization of emotion regulation

\begin{tabular}{|c|c|c|c|c|c|}
\hline \multicolumn{6}{|c|}{ CATEGORY } \\
\hline & & $\begin{array}{l}\text { Frequ } \\
\text {-ency }\end{array}$ & Percent & $\begin{array}{c}\text { Valid } \\
\text { Percent }\end{array}$ & $\begin{array}{l}\text { Cumu- } \\
\text { lative } \\
\text { Percent }\end{array}$ \\
\hline \multirow{4}{*}{$\begin{array}{l}\text { Vali } \\
\text { d }\end{array}$} & Low & 19 & 12.6 & 12.6 & 12.6 \\
\hline & $\begin{array}{c}\text { Curren } \\
\text { tly }\end{array}$ & 85 & 70.9 & 70.9 & 83.5 \\
\hline & Tall & 31 & 16.5 & 16.5 & 100.0 \\
\hline & Total & 135 & 100.0 & 100.0 & \\
\hline
\end{tabular}

\section{DISCUSSION}

There are differences in the level of student emotion regulation. This finding is in line with previous research, which states that the high rate of juvenile delinquency is the result of a lack of ability to manage emotions in a way that is acceptable to norms so that the immaturity of emotions causes individuals to be easily carried away by group influences to perform certain behaviors (negative behavior).

Emotion regulation is a strategy called cognitive reappraisal, which involves changing the way one thinks about a situation to influence one's emotional response [2].

In line with this opinion, emotion regulation itself is interpreted as an adaptive way of responding to emotions (regardless of intensity/reactivity), including receiving responses, controlling behavior in dealing with emotional stress, and the practical use of emotional information.

The ability to control oneself is one of the keys to reducing the occurrence of bullying and lack of concern for others because, with self-control, individuals can feel proud and happy with their situation. Another indication of emotional maturity is that individuals assess the situation critically before reacting emotionally. Thus adolescents can ignore stimuli that previously caused emotional outbursts. Adolescents who are not emotionally mature can be seen from their behavior that tends to be impulsive, lacks concern for others, and lacks a sense of responsibility, and is easily frustrated. Teens who are emotionally immature or low can govern behavioral bullying because they cannot control their emotions with good.

\section{CONCLUSION}

The results of this study indicate that, on average, the 8th-grade students of SMP Negeri in Surabaya have a moderate level of emotional regulation $(70.9 \%)$. Thus, the suggestion for BK teachers is to improve the skills or abilities of students' emotional regulation at low and moderate levels to reduce the tendency of bullying behavior. The findings in this study can be used as recommendations for schools, especially counselors, to design strategies so that students' self-regulation abilities can be improved.

\section{REFERENCES}

[1] A. Darmiany, "Development of Soft-skills Training Model for State Junior High School Students (SMPN) in Mataram City," Journal of the Study of Guidance and Counseling., vol. 1, no. 2, pp.47-54, 2016.

[2] J.J. Gross., \& P.J. Oliver, "Individual differences in two emotion regulation processes: implications for affect, relationships, and well-being," Journal of personality and social psychology, vol. 85, no. 2, pp. $348,2003$.

[3] I.J. Hsieh,, \& Y.Y. Chen, "Determinants of aggressive behavior: Interactive effects of 
emotional regulation and inhibitory control," PLOS
ONE, vol.12,
no.
4, pp
$1-9$,

2017, https://doi.org/10.1371/journal.pone.017565

1 .

[4] I. Irman, "Management of student academic anxiety through emotional regulation training," AlQalb: Journal of Islamic Psychology, vol.6, no.2, pp.62-71, 2015.

[5] D.E. Kurniawan., \& T.A. Pranowo, "Development of a Group Guidance Model with Sociodrama Techniques to Overcome Bullying Behavior," Journal of Counseling Focus, vol.4, no. 1, pp 126-135, 2018 .

[6] H.I.S. Nasution., \& W.F. Hasibuan, "Causes of Verbal Bullying Among Students of SMP IT Ulil Albab Batam," KOPASTA: Journal of the Counseling Guidance Study Program, vol. 2, no. 2, 2015.

[7] Fisherman, "Research Paper: The Effectiveness of emotion Regulation Skills Training on Anxiety and Emotional Regulation Strategies in Adolescent Students," Practical in Clinical Psychology, vol.5, pp.263-269, 2017.

[8] Y.M. Shahada, "Emotional regulation training to reduce aggressive behavior in children," Humanitas: Indonesian Journal of Psychology, vol.10, no. 1, pp. 19-36, 2013. 